\title{
The Classroom Teaching Design and Instruction of College Teachers under the Background of "Double First-rate"
}

\author{
Xiaowei Feng \\ Ideological and Political Department, Xi’an Peihua University, Xi’an, Shaanxi, China, 710125
}

Keywords: college teacher; classroom design; ability cultivation

\begin{abstract}
This paper mainly discusses the reasonable design and instruction skills of classroom teaching under the background of "Double First-rate". The teaching design can fully reflect modern education concept, and give play to the teachers' subjective initiative in teaching and students' independent participation in teaching, which is conductive to the construction of students' knowledge system and the cultivation of students' innovative thinking ability.

Chen Baosheng, the Minister of Education, pointed out, "Take quality as the lifeline of education, and insist on returning to common sense, returning to the duty, returning to the original intention, and returning to the dream. Deepen the reform of the basic education talent training model, launch the "classroom revolution", and strive to cultivate students' innovative spirit and practical ability". Classroom, as the main channel to cultivate talents, to certain extent, decides the talent cultivation mode. However, it is difficult for current classroom mode to train students' necessary quality and key ability to adapt to lifetime development and social development requirement. The development trend of world higher education, pays more attention to "Six C", that is, concept; communication; connection; critical thinking; competence and creativity. Whereas, the cultivation goal of China's higher education is to focus on improving comprehensive quality and application ability, and pay attention to the education concept of "Six C". To realize this goal, objectively, teachers are required to improve their comprehensive quality, and implement classroom teaching with the guidance of systematical and scientific thought and method. Therefore, under the background of "Double First-rate", in-depth discussion on classroom teaching design and instruction of China's college teachers is the necessary requirement of “classroom revolution” in the new era.
\end{abstract}

\section{The Framework Design of Classroom Teaching}

Paying attention to the logic and rigor of knowledge is the advantage of traditional teaching. But where does this knowledge come from and how it is used is the weak link to transforms knowledge into ability. Therefore, in the classroom teaching design, if we can abstract the concept from the actual problem, abstract the logical relationship of the theory from the problem analysis, and build the knowledge system with the main purpose of solving the problem, it should be an effective process of capacity cultivation. In this way, students can fully understand the practical application of the knowledge system while building knowledge, so as to achieve the teaching goal of applying knowledge to solve problems. Therefore, an effective classroom teaching framework is described in detail.

Firstly, to select typical cases and scientifically design difficult problems. Design a suitable case for the content of this lesson, which must be targeted, authentic, have certain connotations to be inspired, and must be the problem that everyone is looking forward to solving. This case shall be thoroughly analyzed and explained, and the key issues to be studied and solved in this lesson shall be summarized. On the one hand, the problems designed should be full with characteristics of exploration, research, openness, and application. Such problems can show the diversity of answers, and such discussion can stimulate students' curiosity, thus expanding the breadth and depth of students' thinking; The design of such problems requires teachers to establish the concept of pursuing the thinking process. In other words, discussing the problem is not only to get the conclusion of the research question as soon as possible, but to fully demonstrate the process of 
students' studying problems, and more importantly, in this process, teachers constantly discover, cultivate and protect the creative thinking of students. On the other hand, the problems designed should be hierarchical. Students' knowledge levels are different. The problem with low difficulty is beneficial to protect students who have difficulty in learning and to stimulate their curiosity. Problems with certain difficulty can help students to challenge the problem research, thus motivating students' learning enthusiasm and realize the goal of "teaching for all”.

Secondly, to explore the connotation of problems and establish the theoretical system of knowledge. The problem is just the introduction, whose main purpose is to serve the teaching content, to establish scientific theories according to the needs of problems, and to build a knowledge system. The establishment of these theories based on solving problems is a conscious behavior. There must be strict reasoning in logic, the extension of the concept and its connotation should be fully discussed, and everything should be discussed around the problems. It is easier for such a theoretical system to connect with the theory and is easier for students to understand.

Thirdly, to reasonably solve problems and train the ability of knowledge transfer. Solving problems and cultivating students' knowledge transfer ability is the aim of classroom teaching and the ultimate goal of teaching design. In this process, to solve design problems reasonably with the established knowledge system is the key to the teaching process and an important means for students to understand and master the knowledge system. Building a theoretical system is the core, and solving problems is the application of theory. This basic theory established through the connection of theory and practice easily and consciously constitute students' knowledge system and enhance the practicality of the theory.

Fourthly, to focus on perfecting the logic and sublimate the classroom teaching content. A complete knowledge system often makes people ignore some potential preconditions, conditions and exceptions, which requires us to reflect the logical perfection of the knowledge system in the teaching design. In addition to summarizing the completeness of the theoretical system established, this logic should also lead to a new round of confusion and thinking for students, and prevent students from generating some complacency and stagnation at the apex of their own thinking. Therefore, the class summary is not a repetition of content, but there must be sublimation and inspiration. The knowledge system of any discipline should have its profound connotation and rich extension, try to dig its connotation, deepen the understanding of knowledge, try to show its extension, leave enough imagination space for students and enhance the ability of innovative thinking.

\section{The Content Design of Classroom Teaching}

Under the classroom teaching framework, organizing teaching content is the center of the entire classroom teaching. Whether the content is full, whether the logic is strict, whether the reasoning is accurate, whether the subject is outstanding, whether the key and difficult points are handled reasonably, etc., should be properly grasped for a qualified teacher. In the design of teaching content, three aspects shall be stressed.

First of all, to be realistic and authentic. "Authenticity" is the source of life that constitutes "beauty". Any piece of art is a unity of truth, goodness, and beauty. The classroom design process is actually a solid preparation of lessons. To design a quality class, in addition to the integration of the knowledge of the subject, teachers are required to have a wealth of practical experience, to understand the hot and difficult issues of the discipline, to understand the urgent needs of society, and to closely integrate discipline construction with social development. Only in this way can teachers be handy, targeted and confident, to avoid the vanity of the content.

Secondly, to learn widely. Teachers always remind themselves of the update of knowledge. The former Soviet Union educator Suhomlinski said, “Only when the teacher's knowledge horizon is unparalleled than the school outline, teachers can become the true masters, artists and poets of the educational process". To this end, learning widely from others with vertical and horizontal development is one of the basic qualities of teachers. Vertically, teachers shall strive to clarify the past and present of the discipline and step into the forefront of the development of the discipline; 
horizontally, teachers are required to propose different issues for different issues, from different teaching materials, different perspectives, and even different disciplines, so as to improve themselves by learning from others.

Thirdly, to advocate the simplicity with the pursuit of effectiveness. Since teachers often have a thorough both western and Chinese knowledge, erudite and informed, this image strengthens students' conviction of what they have learned. If teachers make a complex design, frequently list concepts or opinions that are beyond the ability of the participants to accept, and even they fail to grasp those, which is undoubtedly a blow to the prestige of the instructors and a violation of the basic principles of teaching. In addition, in the process of teaching, it is inevitable to make mistakes, teachers can honestly admit these negligence, and immediately deal with it calmly and decisively. Therefore, in teaching, it is necessary not to say something empty talk, big talks, and unintentional things, which will cause the dissatisfaction of students.

Teaching activities are the bilateral interaction process between teaching and learning. Teachers and students are like two flying wheels, with the bilateral exchange of thoughts and feelings as the axle, driving the car in the common cooperation. It is hard to imagine how a teacher who has a smattering of knowledge and unclear logic will conquer the audience's mind when he comes to the stage. If what a teacher said is meaningless or a teachers just repeat what the book says, how he or she can inspire listeners' creative thinking? Thus, in the design of content, three key points shall be grasped.

First, the content structure shall be strictly logical. The instruction of a lesson should be a complete system, with strict logic structure and theoretical core. The core is the outline of this lesson. Only the teacher grasp the outline, can he or she give a clear lesson. Otherwise, the lesson seems vivid, however, it is the fact of head in the clouds.

Second, the cultivation of temperament and interest shall be vivid. For a problem, if abstract thinking is only used, many concepts, judgments, and reasoning are needed. Most situations will make people unable to understand and reduce people's interests. The drawback of this kind of lesson preparation is that it fails to use imagery thinking. In fact, imagery thinking can often stimulate people's creative thinking ability and give people the imagination.

Third, the bilateral communication shall be emotional and reasonable. In the preparation of lessons, it is necessary to carefully design the scenes of bilateral interactions. The interactive process is closely related to the theme, with clear objectives, and it should be appropriate and emotional. The interactive process is carefully designed to avoid rigid question-based interactions.

\section{The Language Arts of Classroom Teaching}

Suhomlinski said, “The teacher's language cultivation determines the efficiency of students' brain work in the classroom to a considerable extent. A person who lacks good expression skills will not become a competent teacher." So, how to express carefully designed content through the art of language? The general answer is clear, accurate and concise language. But this is easier said than done. Therefore, these three aspects shall be kept in mind.

First, the fluency and intonation of language. In the classroom teaching, fluency and intonation should complement each other, so that the classroom language is in balance. Among them, fluency is the basic requirement of the teaching language. In terms of semantics, fluency is mainly the order, with coherence of meaning, rationality of structure and rationality of expression. The key is to deal with the contradiction between the one-dimensional structure of words (chronological order) and the network structure of thinking. Therefore, the classroom language is designed to follow the rules of old information first and new information next in order; and to consider the effect of the first and last position in content to reduce excessive repetition. The intonation is the interval, transformation and deepening of thinking, which is pause and rhythm reflected in the language. The intonation should grasp the two points of "time" and "degree". "Time" is the timing of pauses, generally to highlight key content, change thinking and inspire thinking. And "degree" is the length of the pause time, to be properly grasped.

Second, the emotion and reasonableness of language. In classroom teaching, emotional language 
is the method, and rational language is the purpose. Only the relationship between the two handled well can the best results be achieved. The language of instruction should be a language with emotions. This kind of emotion comes from the "love", "responsibility" and "honor" of students, also a full devotion to the teaching content, which is generally to instruct and express with the "heart". In this way, teaching language can be spirited with inspiration and appeal. On the other hand, it is easy for emotional language to cause the communication between the teaching objects and create a teaching interaction scene. Whereas, the rational language requires that the language expression taught in the classroom is with rigorous thinking, thorough reasoning, incisive analysis and accurate judgment, to interpret the causes and effects of knowledge, and to clarify the value utility of the theory.

Third, the elegance and popularity of language. The requirement of elegant language is that the language is standardized and reasonable. In the teaching, it is required to use the standard Mandarin as much as possible, and use professional terminology to express the content of the subject. Elegant language expression will give people a sense of seriousness and rigor. However, the excessive elegance easily causes the fatigue of thinking. The purpose of the lecture is to let students understand the abstract concept, which is popularity to let most people understand and accept. This requires the use of popular language expression habit. However, popularity is not equal to vulgarity. Only by combining the two well throughout the whole process can we achieve successful teaching goals.

\section{References}

[1] Xi Jinping. Speech on National Education Conference [N]. Guangming Daily, 2018-09-11 (1).

[2] Zhang Yingqiang. The Cultrual Spirit and Mission of College [M]. Anhui: Anhui Education Press, 2008.

[3] Deng Tao. The Introduction Art of Famous Teacher in Efficient Classroom [M]. Chongqing: Southwest China Normal University Press, 2008.

[4] Hong Chengwen. What Are International Experience of World-class Discipline Development [J]. China Higher Educaiton, 2018, (5). 